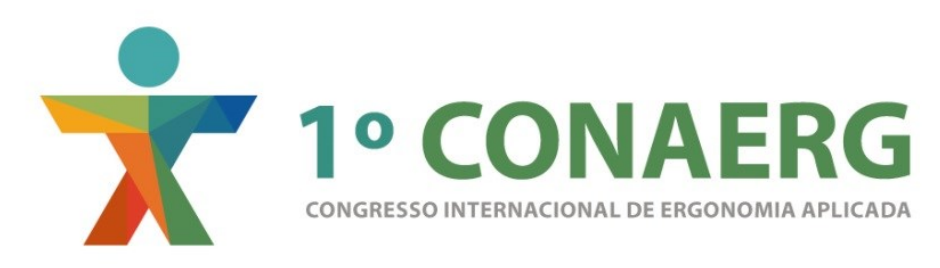

\title{
ANÁLISE POSTURAL NO TRABALHO DE DOCÊNCIA NO ENSINO SUPERIOR
}

\author{
Jeanne Moro (1); \\ Luna Steffen (2); \\ Francine Kaviski (3); \\ Aline Franchini (4); \\ Rodrigo Eduardo Catai (5) \\ (1) UTFPR, Mestrado \\ e-mail: jeannemoro@gmail.com \\ (2) UTFPR, Mestranda \\ e-mail: luna_steffen@hotmail.com \\ (3) UTFPR, Mestranda \\ e-mail: francinek@alunos.utfpr.edu.br \\ (4) UTFPR, Mestranda \\ e-mail: aline.franchini@bol.com.br \\ (4) UTFPR, Doutor \\ e-mail: catai@utfpr.edu.br
}

\begin{abstract}
RESUMO
Professores são profissionais expostos a esforços de baixa carga e desenvolvem suas atividades de forma dinâmica e repetitiva. O presente artigo tem como objetivo fazer uma análise dos desvios posturais de professores do ensino superior, por meio de avaliações posturais utilizando o software RULA e a análise de dores musculares através do diagrama de dor/desconforto - Diagrama de Corlett. Foram analisados cinco professores durante uma aula individual com período em média de duas horas para cada professor. A partir da aplicação do Diagrama de Corlett, foram identificados que alguns professores apresentam desconforto em membros superiores e tronco de intensidade variada.
\end{abstract}

\begin{abstract}
Teachers are professionals exposed low load efforts, and carry out their activities in a dynamic and repetitively way. In order to analyze the postural deviations from teachers working in higher education, through postural assessments using RULA software and analysis of muscle pain through the diagram of pain / discomfort - Corlett diagram. Five teachers and their attitudes were analyzed during a single class period with an average of two hours for each teacher From the application of Corlett diagram, it was identified that some teachers have some discomfort in the upper limbs and trunk with varying intensity.
\end{abstract}

\section{INTRODUÇÃO}

A postura é um arranjo de todos os segmentos corporais a fim da sustentação (LOPES, 2005). O 
corpo humano por sua vez, apresenta uma posição ereta bípede, e, sob diferentes esforços físicos internos e externos, suas partes são submetidas constantemente a reposicionamentos para manter o equilíbrio ou a realização de uma atividade.

O equilíbrio é dado em função dos alinhamentos com o ambiente e o próprio corpo. Sendo assim, quanto maior a carga aplicada sobre o corpo, maior será a pressão sob todos estes segmentos. Uma vez que o corpo se encontra equilibrado as forças irão ser distribuídas e descarregadas no solo igualmente, bem como o corpo disformemente apoiado, receberá esforços descentralizados passíveis de lesões (MCCREARY, 1993; KENDAL, 1995).

As alterações patológicas são reflexo destas sobrecargas e consideradas elevadas à população adulta mundial. Por isso, aos hábitos posturais cabe um processo de educação e de controle de postura adequada, principalmente diante dos frequentes esforços do trabalho (GUADAGNIN e MATHEUS, 2012).

O conceito de biomecânica ocupacional, que estudas as interações entre o trabalho e o homem sob o ponto de vista dos movimentos dos músculos-esqueletais envolvidos e suas consequências. Tem como foco a análise das posturais corporais do trabalho e a aplicação de forças. Muitos produtos e postos de trabalhos inadequados provocam dores musculares, dor e fadiga (AMARAL, 2009).

Professores são profissionais expostos a exemplo desses tipos de esforços, ainda que, de baixa carga, desenvolvem suas atividades de forma dinâmica e repetitiva. Por este motivo, o presente artigo tem como objetivo fazer uma análise dos desvios posturais a partir do trabalho de professores do ensino superior do Paraná, por meio de avaliações posturais e dores musculares.

\section{REVISÃO BIBLIOGRÁFICA}

De acordo com a Ergonomics Research Society, a ergonomia é o estudo do relacionamento entre o homem e seu trabalho, equipamento e ambiente, e particularmente a aplicação dos conhecimentos de anatomia, fisiologia e psicologia na solução dos problemas surgidos desse relacionamento (IIDA, 1992), e é um conjunto de ciências e tecnologias que procura a adaptação confortável e produtiva entre o ser humano e seu trabalho, basicamente procurando adaptar as condições de trabalho às características do ser humano (COUTO, 1995).

De acordo com Wisner (1995, apud ABRAHÃO, PINHO, 2002), a Ergonomia sustenta-se em dois pilares. Sendo um de base comportamental, que permite apreender as variáveis que determinam o trabalho pela via da análise do comportamento, e um outro, subjetivo, que busca qualificar e validar os resultados, ambos com o intuito de elaborar um diagnóstico que vise transformar as condições de trabalho.

A Norma Regulamentadora NR-17, estabelece parâmetros que permitem a adaptação das condições de trabalho às características psicofisiológicas dos trabalhadores, de modo a proporcionar um máximo de conforto, segurança e desempenho eficiente (CARDOSO JUNIOR, 2006).

Os distúrbios e problemas músculo-esqueléticos encontram-se, atualmente, no topo dos indicadores de doenças ocupacionais, quando se enfocam as perturbações na saúde dos trabalhadores. Independentemente do tipo de atividade ou do produto fabricado, do processo e organização do trabalho, as estruturas musculoesqueléticas passam a ser alvo frequente de agressões. As causas dessas agressões são diversas, considerando desde posturas críticas adotadas durante a jornada até fatores psicossociais e emocionais que acabam por acarretar posturas de proteção, que são as posturas estáticas prolongadas (RENNER, 2005).

Ainda segundo o mesmo autor, os principais fatores que induzem à fadiga muscular são trabalho repetitivo, trabalho muscular estático, posturas e gestos críticos (Figura 1).

O trabalho estático é caracterizado por um estado de contração prolongada da musculatura o que normalmenteimplica em um trabalho de manutenção da postura. $\mathrm{O}$ trabalho dinâmico caracteriza-se pela alternância entre a contração e extensão ou tensão e relaxamento (KROEMER, 2005 apud PADILHA 2015). 
Figura 1 - Trabalho Estático e Dinâmico

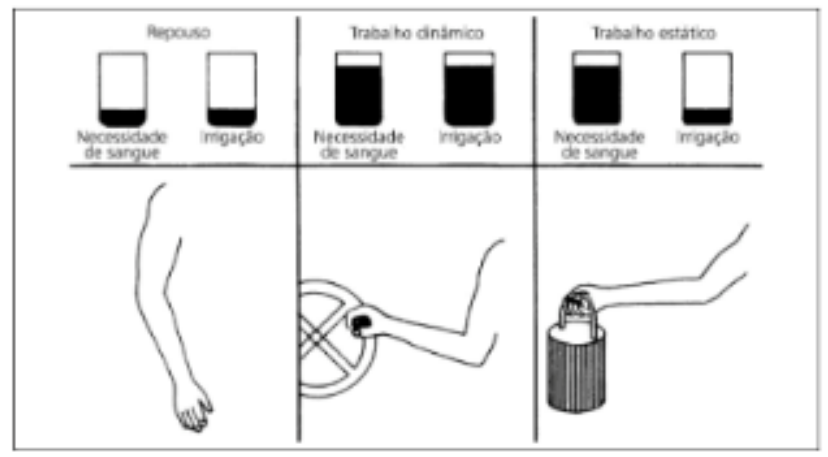

Fonte: Adaptado de Kroemer (2005)

As posturas críticas geralmente estão associadas a postos de trabalho mal projetados, que não permitem um posicionamento anatômico e fisiológico adequado, assim como podem estar associadas a movimentos de flexão e rotação do tronco (RENNER, 2005).

Mendes (2011) especifica que algumas condições do ambiente de trabalho podem contribuir para o processo de adoecimento do trabalhador, como: fatores inadequados no ambiente físico, mobiliários impróprios, ruído excessivo, temperatura elevada; fatores ligados à organização do trabalho como ritmo acelerado de trabalho, ausência de pausas, exigências de produção; fatores psicossociais como estresse, ansiedade, depressão e principalmente, conflitos de relação profissionais (cliente - profissionais - chefes) e, ainda aspectos relacionados às características individuais do trabalhador, como vícios posturais e doenças preexistentes.

Os educadores correm o risco de sofrerem esgotamento físico e mental, levando-se em consideração as dificuldades materiais e psicológicas associadas ao exercício da docência. No Brasil, observou-se um grande número de professores readaptados (afastados temporária ou permanentemente para as atividades administrativas), sendo afetados por uma ou algumas doenças da área da psiquiatria, neurologia, otorrinolaringologia, reumatologia ou mesmo professores que se mantêm em sucessivas licenças de saúde por razões diversas (APEOESP, 2010, apud ALVES et al., 2014).

E entre as exigências ergonômicas do trabalho destacam-se os Distúrbios Osteomusculares Relacionados ao Trabalho - DORT, com alterações provocadas por inflamações dos membros inferiores, como dores nas pernas, presença de varizes provocadas pelo número de horas seguidas em pé, incidência de má postura corporal, dores lombares e, lesões por esforço repetitivo (SORATO; MARCOMIN, 2007)

As posturas desconfortáveis e antiergonômicas aparecem em alguns estudos. Estes enfatizam a associação e presença de dores constantes no pescoço e nos membros superiores, sendo acentuadas as relacionadas a posturas inadequadas ao corrigir as tarefas dos alunos, a permanecer em pé por um longo período de tempo, realizando movimentos repetitivos como escrever no quadro, usar o computador, ou mesmo corrigir cadernos (PEREIRA et. al, 2009; WEBBER e VERGANI, 2010; SOUZA e LEITE, 2011).

Segundo Vidal (2002), as Análises Ergonômicas "são análises quantitativas e qualitativas que permitem a descrição e a interpretação do que acontece na realidade da atividade enfocada".

McAtamney \& Corlett (1993), propuseram um método chamado RULA (Rapid Upper Limb Assessment) para a execução de avaliação rápida dos danos potenciais aos membros superiores, em função da postura adotada pelo profissional. O método avalia a postura do pescoço, tronco e membros superiores (braço, antebraço e mãos) e relaciona com o esforço muscular e a carga externa a que o corpo está submetido. Por meio de diagramas de postura do corpo humano e tabelas é possível realizar a avaliação da exposição aos fatores de risco. Os fatores de risco considerados são o número de movimentos, o trabalho muscular estático, a força, a postura de trabalho determinada pelo equipamento e mobiliário e o tempo de trabalho sem pausa. 
Segundo Capelletti (2015) o método RULA é indicado para analisar a sobrecarga concentrada no pescoço e membros superiores, utiliza diagramas para facilitar a identificação das amplitudes de movimentos nas articulações de interesse como também avalia o trabalho muscular estático e as forças exercidas pelos segmentos em análise. Devido à facilidade e confiabilidade dos resultados obtidos, esse método é bastante utilizado na análise ergonômica de posturas, atividades e postos de trabalho.

No software Ergolândia, o método RULA é composto por diagramas de posturas corporais e três tabelas de pontuação para avaliar a exposição a fatores de risco. Os segmentos corporais são considerados em dois grupos: o grupo A é formado pelos membros superiores e o grupo B pela cervical, tronco e membros inferiores; cada segmento é pontuado conforme o diagrama (no caso, por meio da análise das imagens fotográficas) e os valores são combinados nas tabelas; a esses dados são somadas pontuações para cargas adicionais de movimento estático ou repetitivo (músculo) e força excessiva ou externa suportada pelo funcionário (força). $O$ valor obtido nos grupos $A$ e $B$ são relacionados em uma última tabela em que se obtém a pontuação final, que varia de 1 a 7 (Tabela 1); cada faixa de pontuação corresponde a um nível de intervenção ergonômica necessária, que varia de um (postura aceitável) a quatro (requer mudanças imediatas) (MCATAMNEY, CORLETT,1993).

Tabela 1 - Pontuação e níveis de ação do RULA

\begin{tabular}{c|c|l} 
PONTUAÇĀO & NIVEL DE AÇÄO & \multicolumn{1}{|c}{ INTERVENÇĀO } \\
\hline $10 u 2$ & 1 & Postura aceitável \\
\hline 3 ou 4 & 2 & $\begin{array}{l}\text { Deve-se realizar uma observação. } \\
\text { Podem ser necessárias mudanças. }\end{array}$ \\
\hline 5 ou 6 & 3 & $\begin{array}{l}\text { Deve-se realizar uma investigação. } \\
\text { Devem ser introduzidas mudanças. }\end{array}$ \\
\hline 7 & 4 & $\begin{array}{l}\text { Devem ser introduzidas mudanças } \\
\text { imediatamente. }\end{array}$
\end{tabular}

Fonte: MCATAMNEY, CORLETT,1993

\section{METODOLOGIA}

Os métodos apropriados para uma investigação ergonômica são o fenomenológico e o dialético, visto que em estudos desse tipo é preciso investigar a satisfação humana no trabalho. O primeiro tipo de método, de acordo com a etimologia procura compreender e interpretar fenômenos, ou seja, estuda os fenômenos utilizando-se de dados qualitativos.

Desde forma, para este estudo foi utilizada o método qualitativo observacional de cinco professores e suas respectivas posturas durante as aulas ministradas em nível universitário no Estado do Paraná.

A análise dos professores foi realizada durante o período de uma aula com duração média de duas horas cada onde foi realizada a observação e registro fotográfico da atividade do professor. Posteriormente os professores preencheram o diagrama de dor/desconforto Diagrama de Corlett, com escala variante de 1 a 7 , identificando a intensidade de dor e também um questionário com aspectos físicos gerais.

A partir dos registros fotográficos foi escolhida uma posição de referência, baseado no conceito biomecânico, na qual o professor permaneceu a maior parte do tempo de aula. Posteriormente, foi aplicada a ferramenta de análise RULA e comparado com os dados de aspectos físicos do questionário, e com os valores de intensidade de dor apresentados no Diagrama de Corllet. 


\section{RESULTADOS E DISCUSSÕES}

\subsection{Resultados da Aplicação da Ferramenta Rula}

A partir das imagens fotográficas obtidos durante o levantamento observacional foram feitas as análises posturais no software RULA. Cada professor foi analisado em relação aos alinhamentos dos membros superiores e tronco. Foram considerados aspectos como postura estática ou repetitiva por minuto. É importante ressaltar que para a análise do grupo A e do grupo B a carga definida é menor do que $2 \mathrm{~kg}$ intermitente, caracterizando assim a atividade de baixo impacto.

Como resultados da aplicação do RULA obtiveram-se as planilhas indicando a pontuação e o nível de ação para a intervenção do hábito postural do profissional.

A postura do professor 01 é caracterizada pela permanência do grupo A: braço entre $-20^{\circ} \mathrm{e}$ $+20^{\circ}$ em situação de abdução, antebraço entre $60^{\circ}$ e $100^{\circ}$ sem rotação e punho entre $-15^{\circ} \mathrm{e}$ $+15^{\circ}$ com rotação média. Em relação ao grupo $B$ pescoço de $0^{\circ}$ a $10^{\circ}$ com rotação, tronco de $0^{\circ}$ a $20^{\circ}$ sem rotação, e pernas/pés bem apoiados e equilibrados (Figura 2). O resultado da análise feita pelo software RULA apresentou para este profissional a pontuação final 30 que gera a necessidade de intervenção de nível de ação 2 , de acordo com a pontuação e níveis de ação da ferramenta RULA.

Figura 2 - Análise RULA para o professor 1
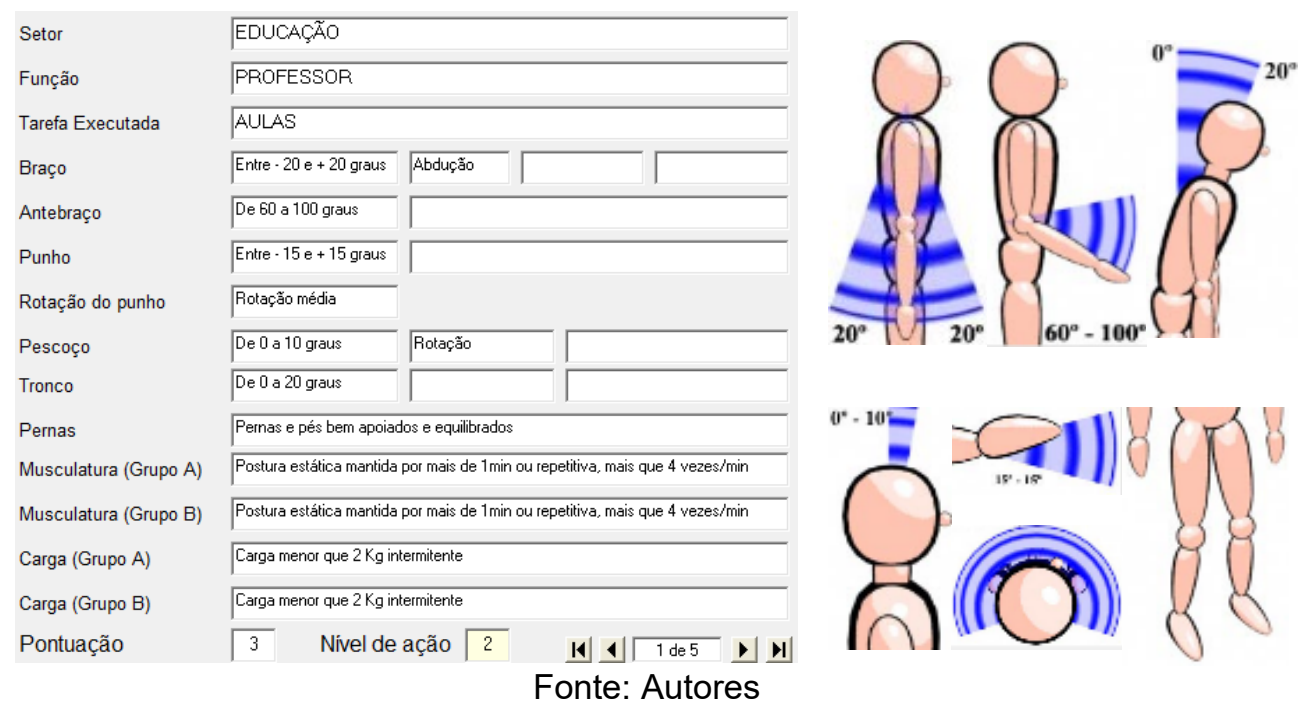

A postura do professor 02 é caracterizada pela permanência do grupo A: braço entre $-20^{\circ} \mathrm{e}$ $+20^{\circ}$ sem abdução, antebraço entre $0^{\circ}$ e $60^{\circ}$ sem rotação e punho entre $-15^{\circ}$ e $+15^{\circ} \mathrm{com}$ rotação média. Em relação ao grupo $\mathrm{B}$ pescoço de $0^{\circ}$ a $10^{\circ}$ com rotação, tronco ereto sem rotação, e pernas/pés bem apoiados e equilibrados (Figura 3 ).

O resultado da análise feita pelo software RULA para este professor apresentou igualmente a pontuação final 3 o que gera a necessidade de intervenção de nível de ação 2 , de acordo com a pontuação e níveis de ação da ferramenta RULA. 
Figura 3 - Análise RULA para o professor 2
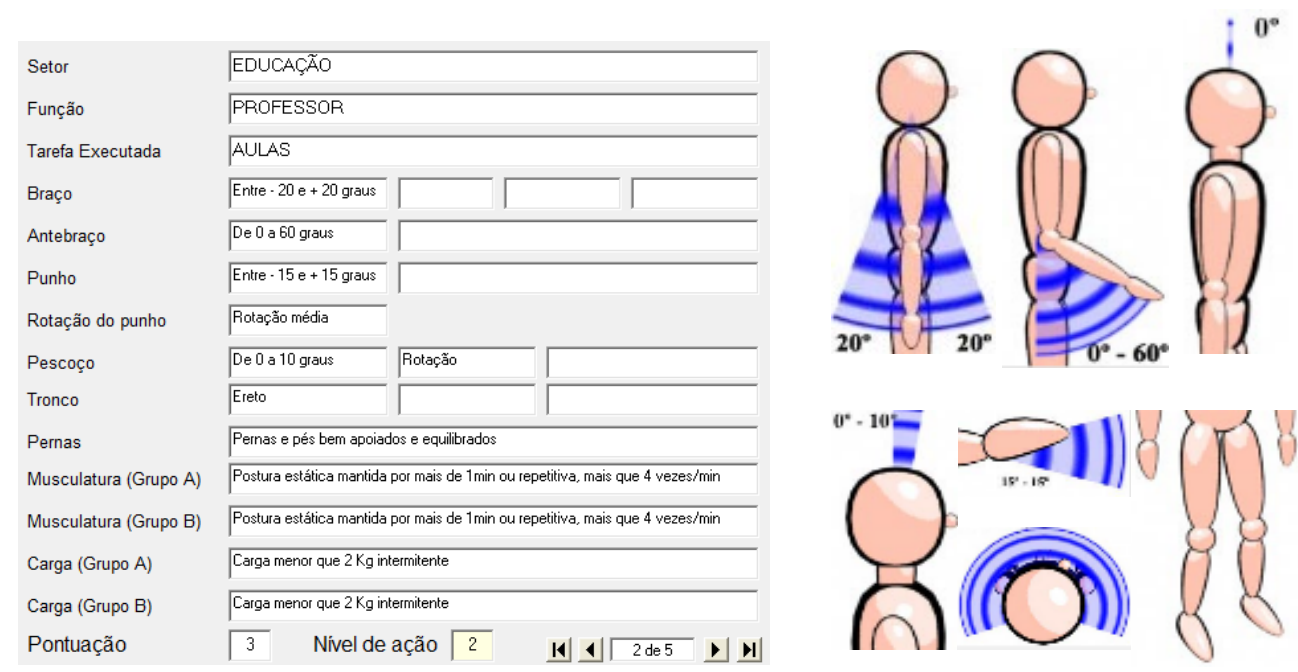

Fonte: Autores

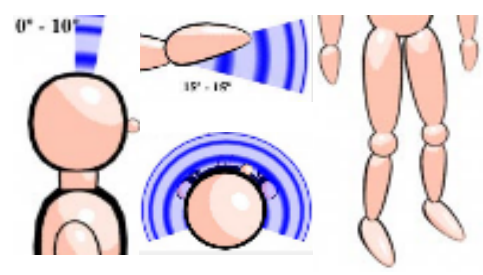

A postura do professor 03 é caracterizada pela permanência do grupo A: braço entre $20^{\circ} \mathrm{e}$ $45^{\circ} \mathrm{com}$ abdução, antebraço entre $60^{\circ}$ e $100^{\circ}$ sem rotação e punho $0^{\circ} \mathrm{com}$ rotação média. Em relação ao grupo $\mathrm{B}$ pescoço de $0^{\circ}$ a $10^{\circ}$ com rotação e inclinação lateral, tronco ereto com rotação, e pernas/pés bem apoiados e equilibrados (Figura 4).

$O$ resultado da análise feita pelo software RULA para este professor apresentou a pontuação final 4 o que gera a necessidade de intervenção de nível de ação 2, de acordo com a pontuação e níveis de ação da ferramenta RULA.

Figura 4 - Análise RULA para o professor 3
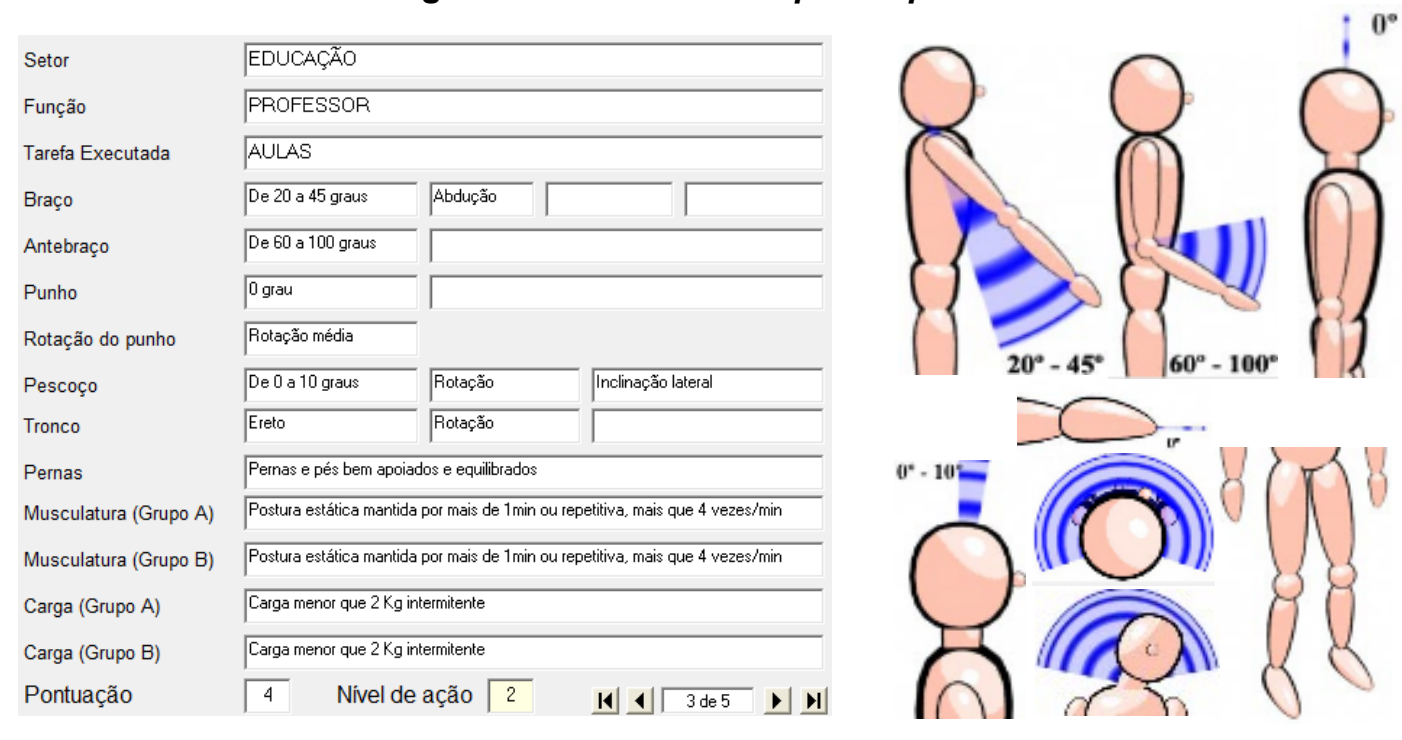

Fonte: Autores

A postura do professor 04 é caracterizada pela permanência do grupo A: braço entre $45^{\circ}$ a $90^{\circ} \mathrm{com}$ abdução, antebraço entre $0^{\circ}$ e $60^{\circ}$ sem rotação e punho entre $-15^{\circ}$ e $+15^{\circ} \mathrm{com}$ rotação média.

Em relação ao grupo $B$ pescoço de $0^{\circ}$ a $10^{\circ}$ com rotação, tronco ereto sem rotação, e pernas/pés bem apoiados e equilibrados (Figura 5).

O resultado da análise feita pelo software RULA para este professor apresentou igualmente a pontuação final 4 o que gera a necessidade de intervenção de nível de ação 2 , de acordo com a pontuação e níveis de ação da ferramenta RULA. 
Figura 5 - Análise RULA para o professor 4
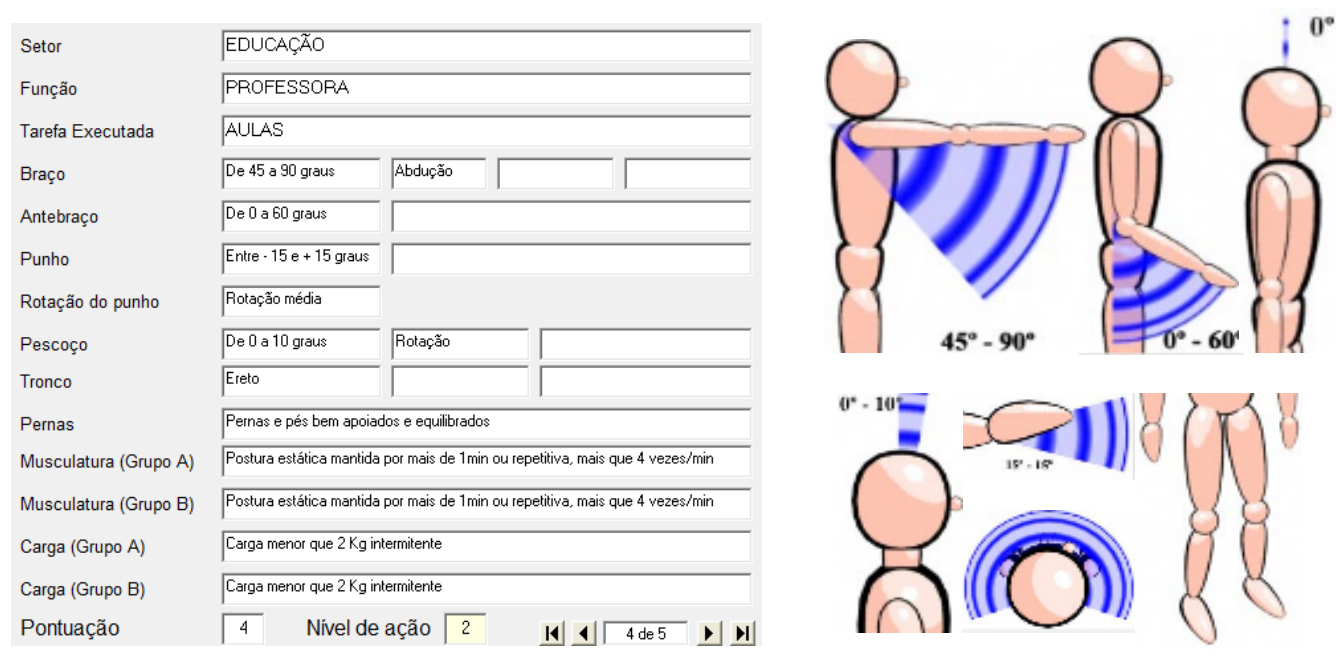

Fonte: Autores

A postura do professor 05 é caracterizada pela permanência do grupo A: braço entre $-20^{\circ} \mathrm{e}$ $+20^{\circ} \mathrm{com}$ abdução, antebraço entre $60^{\circ}$ e $100^{\circ}$ sem rotação e punho $0^{\circ} \mathrm{com}$ rotação média. Em relação ao grupo $\mathrm{B}$ pescoço de $10^{\circ}$ a $20^{\circ}$ com rotação, tronco ereto sem rotação, e pernas/pés bem apoiados e equilibrados (Figura 6).

Figura 6 - Análise RULA para o professor 5

Setor
Função
Tarefa Executada
Braço
Antebraço
Punho
Rotação do punho
Pescoço
Tronco
Pernas
Musculatura (Grupo A)
Musculatura (Grupo B)
Carga (Grupo A)
Carga (Grupo B)
Pontuação
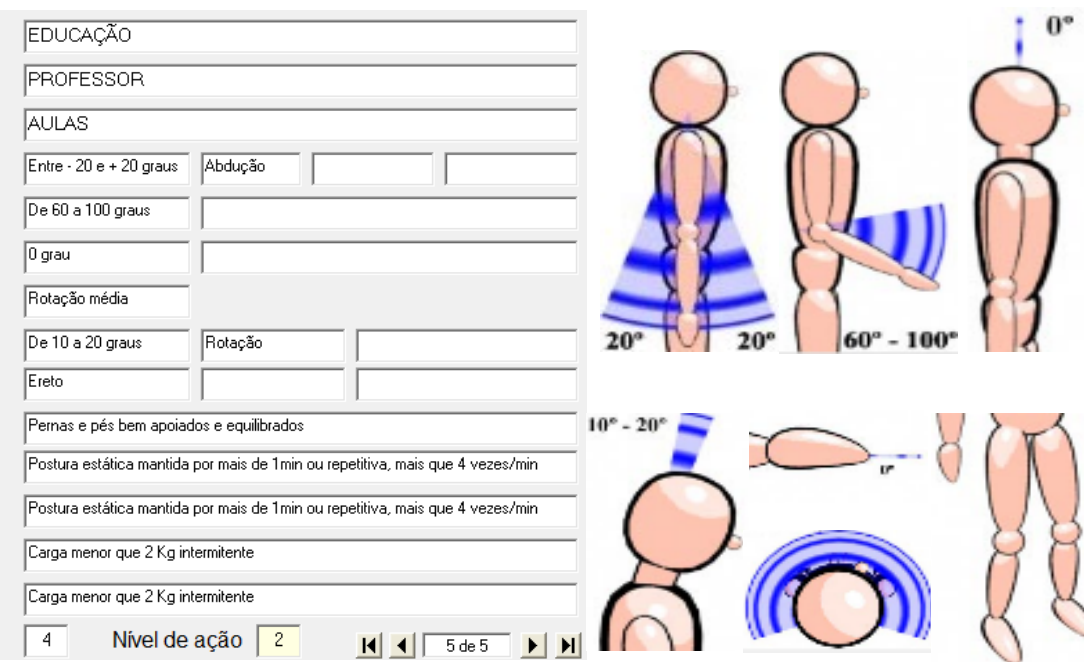

Fonte: Autores

O resultado da análise feita pelo software RULA para este professor apresentou igualmente a pontuação final 4 o que gera a necessidade de intervenção de nível de ação 2 , de acordo com a pontuação e níveis de ação da ferramenta RULA.

A partir destes resultados do RULA, foi observado que professores que apresentaram pontuação final 3 , ministram aulas em pé utilizando projetor e meios digitais. $E$ professores que apresentaram a pontuação final 4 , ministram aulas em pé ou sentado, utilizando-se de quadro negro ou assessoramento individual de trabalho (Quadro 1). 


\section{Quadro 1 - Caracterização dos professores e resultado da análise RULA}

\begin{tabular}{|c|c|c|c|c|c|c|}
\hline \multirow{8}{*}{ 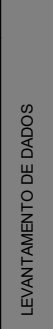 } & & PROFESSOR 1 & PROFESSOR 2 & PROFESSOR 3 & PROFESSOR 4 & PROFESSOR 5 \\
\hline & IDADE & 49 & 36 & 27 & 44 & 49 \\
\hline & SEXO & M & M & M & $\mathrm{F}$ & M \\
\hline & ALTURA (m) & 1,82 & 1,75 & 2,05 & 1,63 & 1,76 \\
\hline & PESO (KG) & 88 & 120 & 97 & 54 & 72 \\
\hline & ATIV.FÍSICA & $\mathrm{N}$ & $\mathrm{N}$ & s & S & $\mathrm{N}$ \\
\hline & TEMPO DE PROFISSÃO (anos) & 20 & 12 & 4 & 10 & 14 \\
\hline & CARGA HORÁRIA SEMANAL (h em sala) & 15 & 15 & 16 & 12 & 20 \\
\hline \multirow{5}{*}{ 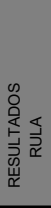 } & METODOLIGIA DA AULA & Slide & Slide & Quadro negro & Quadro negro & Assessoria \\
\hline & POSTURA (predom. aulas) & PÉ & PÉ & $P E ́$ & PÉ & SENTADO \\
\hline & NÍVEL DE AÇÃO & 2 & 2 & 2 & 2 & 2 \\
\hline & PONTUAÇÃO & 3 & 3 & 4 & 4 & 4 \\
\hline & INTERVENÇÃO & \multicolumn{2}{|c|}{$\begin{array}{c}\text { Deve-se realizar uma } \\
\text { observação. }\end{array}$} & \multicolumn{3}{|c|}{ Podem ser necessárias mudanças. } \\
\hline
\end{tabular}

M=MASCULINO; F=FEMININO; N=NÃO; S=SIM

Fonte: Autores

\subsection{Análise de dor-relação do Diagrama de Corlett}

A partir da aplicação do diagrama de dor/desconforto - Diagrama de Corlett, onde são relacionados os aspectos físicos e de dor, foram identificados que alguns professores apresentam desconforto nos membros superiores e tronco com intensidade variando de $1 \mathrm{a}$ 7. Dos cinco profissionais entrevistados, apenas dois não tiveram queixa de dores.

\section{Quadro 2 - Resultados da aplicação do Diagrama de Corlett}

\begin{tabular}{|c|c|c|c|c|c|c|c|}
\hline \multicolumn{8}{|c|}{ ANÁLISE POSTURAL DE PROFESSORES APÓS EXERCÍCIO DE AULAS } \\
\hline & & & PROFESSOR 1 & PROFESSOR 2 & PROFESSOR 3 & PROFESSOR 4 & PROFESSOR 5 \\
\hline \multirow{11}{*}{ 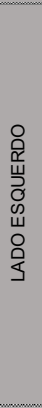 } & 2 & OMBRO & 0 & 0 & 0 & 0 & 0 \\
\hline & 4 & BRAÇO & 0 & 0 & 0 & 0 & 0 \\
\hline & 10 & COTOVELO & 0 & 0 & 0 & 0 & 0 \\
\hline & 12 & ANTEBRAÇO & 0 & 0 & 0 & 0 & 0 \\
\hline & 14 & PUNHO & 0 & 0 & 0 & 0 & 0 \\
\hline & 16 & MÃO & 0 & 0 & 0 & 0 & 0 \\
\hline & 18 & COXA & 0 & 0 & 0 & 0 & 0 \\
\hline & 20 & JOELHO & 0 & 7 & 0 & 0 & 0 \\
\hline & 22 & PERNA & 0 & 5 & 0 & 0 & 0 \\
\hline & 24 & TORNOZELO & 0 & 0 & 0 & 0 & 0 \\
\hline & 26 & PÉ & 0 & 0 & 1 & 0 & 0 \\
\hline \multirow{11}{*}{ 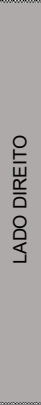 } & 3 & OMBRO & 0 & 0 & 5 & 0 & 0 \\
\hline & 6 & BRAÇO & 0 & 0 & 0 & 0 & 0 \\
\hline & 11 & COTOVELO & 0 & 0 & 0 & 0 & 0 \\
\hline & 13 & ANTEBRAÇO & 0 & 0 & 0 & 0 & 0 \\
\hline & 15 & PUNHO & 0 & 0 & 0 & 0 & 0 \\
\hline & 17 & MÃO & 0 & 0 & 0 & 0 & 0 \\
\hline & 19 & COXA & 0 & 0 & 0 & 0 & 0 \\
\hline & 21 & JOELHO & 0 & 7 & 0 & 0 & 0 \\
\hline & 23 & PERNA & 0 & 5 & 0 & 0 & 0 \\
\hline & 25 & TORNOZELO & 0 & 0 & 0 & 0 & 0 \\
\hline & 27 & PÉ & 0 & 0 & 1 & 0 & 0 \\
\hline \multirow{6}{*}{$\begin{array}{l}0 \\
\text { Z } \\
0 \\
\mathbb{x}\end{array}$} & 0 & PESCOÇO & 7 & 0 & 0 & 0 & 0 \\
\hline & 1 & CERVICAL & 8 & 0 & 0 & 0 & 0 \\
\hline & 5 & COSTAS SUPERIOR & 0 & 0 & 0 & 0 & 0 \\
\hline & 7 & COSTAS MEIO & 0 & 0 & 0 & 0 & 0 \\
\hline & 8 & COSTAS INFERIOR & 7 & 0 & 4 & 0 & 0 \\
\hline & 9 & BACIA & 0 & 0 & 0 & 0 & 0 \\
\hline
\end{tabular}

Fonte: Autores 
O professor 01 , apresentou dor no pescoço com nível 7, dor na cervical com nível 8 e costas inferior com nível 7. O professor 02, apresentou dor nos joelhos com nível 7 e nas pernas com nível 5. O professor 03, apresentou dor nos pés com nível 1 e no ombro esquerdo com nível 5 (Quadro 2).

As regiões de desconforto indicadas pelos professores pode ser justificada devido a que a maioria dos professores estudados ministra aulas em pé, o que pode acarretar dor nas pernas, pés e joelhos. Neste caso, possivelmente, também os fatores físicos e de grau de sedentarismo influenciem este quadro de dor. Já a dor na cervical, pescoço e ombro pode ser relacionada com a utilização do quadro negro para escrita e do pointer usado para a passagem de slides, com relevante movimentação dessas partes corporais (Figura 7).

\section{Figura 6 - Análise RULA para o professor 5}

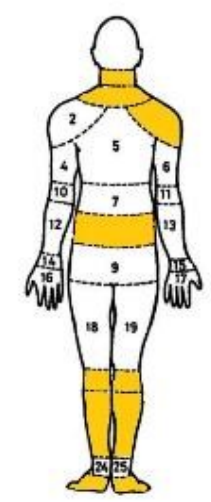

Fonte: Autores

\section{CONCLUSÃO}

Vários fatores contribuem para que um profissional mantenha-se saudável, entre eles os fatores físicos do ambiente de trabalho e os fatores físicos pessoais como a preocupação com os movimentos do corpo e as posturas durante o trabalho.

Neste estudo direcionado aos professores do ensino superior pode-se observar que os professores que ministram aulas utilizando quadro negro ou assessorando os alunos na posição sentado, apresentaram os maiores níveis de pontuação, grau 4, na análise do software RULA, em que podem ser necessárias algumas mudanças posturais.

Já os professores que obtiveram a menor pontuação na análise do RULA, ministram aulas expositivas utilizando recursos como o slideshow.

Deve-se salientar que algumas das dores assinaladas pelos professores no Diagrama de Corllet podem ter influência de hábitos de vida ou vícios posturais e não propriamente devido a postura adotada em sala de aula.

Neste estudo não foram encontradas relações do tempo de exercício da profissão com os desconfortos relatados pelos docentes no Diagrama de Corllet.

Ficou clara a necessidade da continuidade de estudos na área para observar também a influência das variáveis do ambiente de trabalho no bem estar do professor em sala de aula e também incentivar adequações dos hábitos de postura de profissionais da área focando um autocontrole postural. 


\section{REFERÊNCIAS BIBLIOGRÁFICAS}

ABRAHÃO, Júlia Issy; PINHO, Diana Lúcia Moura. As transformações do trabalho e desafios teórico-metodológicos da Ergonomia. Universidade Federal do Rio Grande do Norte, 2002.

ALVES, Cacilda S.; DE ARAÚJO, Mickaell Medeiros; AGUIAR, Carlos Helton A. Postura Ergonômica Do Profissional Docente: um estudo de caso do centro de atenção integrada à criança e ao adolescente (CAIC) Senador Carlos Jereissati, em Russas-CE. TECNOLOGIA \& INFORMAÇÃO-ISSN 2318-9622, v. 1, n. 3, p. 20-32, 2014.

AMARAL, F. A. Ergonomia: Notas de aula de ergonomia - Curso de Arquitetura e Urbanismo. Universidade Federal do Maranhão. 2009. Disponível em: http://www.luzimarteixeira.com.br/wpcontent/uploads/2009/09/o-que-e-ergonomia1.pdf.

BRASIL, Ministério do Trabalho. Norma regulamentadora 17 - NR17. Manual de legislação Atlas, $79^{a}$ Ed. São Paulo: Atlas, 2015d.

CAPELETTI, Ben Hur Giovani Mascarello. Aplicação do método RULA na investigação da postura adotada por operador de balanceadora de pneus em um centro automotivo. Monografia de Especialização curso de Pós Graduação em Engenharia de Segurança do Trabalho, Departamento Acadêmico de Construção Civil, Universidade Tecnológica Federal do Paraná, UTFPR.2015

CARDOSO JUNIOR, Moacyr Machado. Avaliação Ergonômica: Revisão dos Métodos para Avaliação Postural. Ergonomic Assessment: Postural Assessment Methods Review. Revista produção online, v. 6, n. 3, p. 133, 2006.

COUTO, Hudson de Araújo. Ergonomia aplicada ao trabalho: manual técnico da máquina humana. Belo Horizonte : ERGO Editora, 1995.

FERREIRA, Léslie P., PENHA Patrícia J., CAPOROSSI, Carollina, FERNANDES, Ana C. N. Professores Universitários: descrição de características vocais e posturais. Distúrb Comun, São Paulo, n. 23(1), págs 43-49, abril, 2011. Disponível em: http://revistas.pucsp.br/index.php/dic/article/view/8044

GUADAGNIN, Eliane C., MATHEUS Silvana C. Prevalência De Desvios Posturais de Coluna Vertebral em Escolares. Revista Brasileira de Ciências da Saúde, ano 10, n. 31, jan/mar 2012. Disponível em: http://seer.uscs.edu.br/index.php/revista_ciencias_saude/article/view/1463

IIDA, Itiro. Ergonomia projetos e produção. São Paulo : Edgar Blücher Ltda., 1992.

KENDALL F. P, MCCREARY E. K, Provance PG. Músculos, provas e funções. 4a ed. São Paulo (SP): Editora Manole; 1995.

KROEMER, K. H. E; GRANDJEAN, Etienne. Manual de ergonomia: adaptando o trabalho ao homem. $5^{a}$ ed. Trad. Lia Buarque de Macedo Guimarães. Porto Alegre: Bookman, 2005.

LIMA, João Ademar de Andrade. Metodologia de análise ergonômica. Monografia de Especialização em Engenharia de Produção)- Departamento de Engenharia de Produção/CT/UFPB. 73p, 2003.

MCATAMNEY, L.; CORLETT, E.N. RULA: a survey method for the investigation of work-related upper limb disorders. Applied Ergonomics,v. 24, n.2 p. 91-99, 1993.

PADILHA, Ricardo Antonio Bettinelli. Termografia aplicada à análise ergonômica em montadora de veículos. Monografia de Especialização. Universidade Tecnológica do Estado do Paraná. Especialização em Engenharia de Segurança do Trabalho. 2015. 
PATRÍCIO, Susana R.R.; MONTEIRO, Luciano F.; COSTA, Marconi F. ASPECTOS ERGONÔMICOS DO TRABALHO: Um estudo da saúde ocupacional no setor de processamento de dados de uma clínica. XXIX ENCONTRO NACIONAL DE ENGENHARIA DE PRODUÇÃO - A Engenharia de Produção e o Desenvolvimento Sustentável: Integrando Tecnologia e Gestão. Out, 2009. Disponível em; http://www.abepro.org.br/biblioteca/enegep2009_TN_STO_094_639_12559.pdf

RENNER, J. S. (2005). Prevenção de distúrbios osteomusculares relacionados ao trabalho. Boletim da saúde, 19(1), 73-80.

SILVA, Lorena R. F.., SANDOVAL, Renato A. ANÁLISE DOS DISTÚRBIOS POSTURAIS DE PROFESSORES DE EDUCAÇÃO FÍSICA NO CONTEXTO DA PRÁTICA EM ACADEMIA. Revista Digital EFDeportes. Buenos Aires, ano 17, $\mathrm{n}^{\circ}$ 175, dez, 2012. Disponível em; http://www.efdeportes.com/efd175/disturbios-posturais-de-professores-de-educacao-fisica.htm 